Revista Eletrônica do Mestrado em Educação Ambiental

\title{
Ciência, técnica e tecnologia: da dominação da natureza à geração de riscos e as
}

\author{
alternativas socioambientais
}

\author{
Guillermo Ramón Velásquez Castel ${ }^{1}$ \\ Universidade Tecnológica Federal do Paraná \\ http://orcid.org/0000-0002-1895-6292 \\ Hieda Maria Pagliosa Corona ${ }^{2}$ \\ Universidade Tecnológica Federal do Paraná \\ http://orcid.org/0000-0003-1790-5423 \\ Giovanna Pezarico ${ }^{3}$ \\ Universidade Tecnológica Federal do Paraná \\ http://orcid.org/0000-0001-5576-6685
}

Resumo: As concepções de ciência moderna e as técnicas associadas que se materializaram em modos de produzir e consumir nas sociedades contemporâneas, influenciaram e modificaram a relação do homem, entre eles, e com o ambiente natural, gerando riscos para a sociedade e a natureza. Neste artigo, apresenta-se um debate sobre a relação entre ciência, técnica e tecnologia, observando a intervenção dos seres humanos na transformação e uso de recursos naturais, que, ao romper com o processo metabólico, gera riscos que se constituem em ameaça à vida no planeta Terra. O ponto de partida é levar em consideração a crítica ao modelo epistêmico e cultural a partir

\footnotetext{
${ }^{1}$ Possui graduação em Licenciatura en Sociología - Universidad de Oriente (2010). Mestre em Educación: Mención Educación Superior pela Universidad Pedagógica Experimental Libertador (2017). Mestre em Desenvolvimento Regional pela Universidade Tecnológica Federal do Paraná (2019). Doutorando do Programa de Pós-Graduação em Sociologia pela Universidade Federal do Rio Grande do Sul. Foi Assistente Social na Universidad Pedagógica Experimental Libertador. Tem experiência na área de Sociologia, com ênfase em Sociologia. e-mail: guillermorvc@ gmail.com

${ }^{2}$ Possui graduação em Ciências Sociais pela Universidade Federal do Paraná, mestrado em Sociologia pela Universidade Federal do Paraná, doutorado em Meio Ambiente e Desenvolvimento pela Universidade Federal do Paraná, pósdoutorado em Desenvolvimento Socioambiental pelo Ladyss/Paris X (2012) e pós-doutorado em Desenvolvimento Rural pelo PGDR/UFRGS (2013). Professora Permanente e Bolsista-sênior (Fundação Araucária/SETI/PR e Capes) do Programa de Pós-graduação em Desenvolvimento Regional da Universidade Tecnológica Federal do Paraná. Professora permanente do Programa de Pós-graduação em Políticas Sociais e Dinâmicas Regionais da Unochapecó. e-mail: hiedacorona@hotmail.com.

${ }^{3}$ Possui graduação em graduação em Administração pela Universidade Tecnológica Federal do Paraná (UTFPR) Sudoeste (2004) e Direito pela Faculdade Mater Dei (2005). É Doutora em Tecnologia - Programa de Pós-Graduação em Tecnologia - PPGTE/UTFPR - Linha de pesquisa Tecnologia e Trabalho. É docente permanente do Programa de PósGraduação em Desenvolvimento Regional - UTFPR- Campus Pato Branco e do Programa de Pós-Graduação em Administração da UTFPR-Campus Curitiba. Realiza pesquisas nas áreas de Administração, Tecnologia, Educação e Desenvolvimento. e-mail: gpezarico@gmail.com
} 
da teoria da estruturação, em que a tríade ciência, técnica e tecnologia conduzem a um caminho possível para enfrentar as consequências e riscos sociais e ambientais que elas mesmas têm ajudado a configurar, por meio da modernização ecológica. Em seguida, problematiza-se essa solução na medida em que ela está circunscrita a uma determinada configuração teórica e prática que não altera as bases que geraram tais riscos. Por fim, conclui-se sobre a necessidade de levar em conta a complexidade das relações entre ciência, técnica e tecnologia na construção de uma racionalidade ambiental que conduza à sustentabilidade. Sustentabilidade que esteja vinculada à diversidade ecológica e cultural em que estejam presentes múltiplos desenvolvimentos.

Palavras-chave: Ciência e tecnologia. Formulação de riscos. Modernização ecológica.

\title{
Ciencia, técnica y tecnología: de la dominación de la naturaleza a la generación de
}

\section{riesgos y las alternativas socioambientales}

Resumen: Las concepciones de la ciencia moderna y las técnicas asociadas que se materializaron en modos de producir y consumir en las sociedades contemporáneas, influenciaron y modificaron la relación del hombre con el medio ambiente natural, generando riesgos para la sociedad y la naturaleza. En este artículo se presenta un debate sobre la relación entre ciencia, técnica y tecnología, observando la intervención de los seres humanos en la transformación y uso de los recursos naturales, que, al romper con el proceso metabólico, genera riesgos que se constituyen en amenazas para el planeta Tierra. Como punto de partida se considera la crítica al modelo epistémico y cultural a partir de la teoría de la estructuración, en el que la triada ciencia, técnica y tecnología conducen a un camino posible, por medio de la modernización ecológica, para enfrentar las consecuencias y los riesgos ambientales que ellas mismas han ayudado a configurar. Seguidamente, se problematiza esa solución en la medida en que ella está circunscrita a una determinada configuración teórica y práctica que no altera las bases que generaron tales riesgos. Por último, se concluye sobre la necesidad de considerar a la complejidad de las relaciones entre ciencia, técnica y tecnología en la construcción de una racionalidad ambiental que conduzca a la sustentabilidad. Una sustentabilidad que esté vinculada a la diversidad ecológica y cultural en la que estén presentes múltiples desarrollos.

Palabras claves: Ciencia y tecnología. Formulación de riesgos. Modernización ecológica.

\section{Science, technology and technology: from domination of nature to risk generation}

\section{and socio-environmental alternatives}

\begin{abstract}
The conceptions of modern science and the associated techniques that materialized in ways of producing and consuming in contemporary societies, influenced and modified the relationship of man, among them, and with the natural environment, generating risks for society and nature. This article presents a debate on the relationship between science, technique and technology, observing the intervention of human beings in the transformation and use of natural resources, which, by breaking with the metabolic process, generates risks that constitute a threat to life on the planet Earth. The starting point is to take into account the criticism of the epistemic and cultural model from the theory of structuring, in which the triad science, technique and technology lead to a possible path to face the social and environmental consequences and risks that they themselves have helped to be configured, through ecological modernization. Then, this solution is problematized as it is limited to a certain theoretical and practical configuration that does not change the bases that generated such risks. Finally, we conclude about the need to take into account the complexity of the relations between science, technique and technology in the construction of an environmental rationality that leads to sustainability. Sustainability that is linked to ecological and cultural diversity in which multiple developments are present.
\end{abstract}

Keywords: Science and technology. Risk formulation. Ecological modernization. 


\section{Introdução}

O binômio composto pela ciência e a tecnologia tem trazido com seu desenvolvimento mudanças importantes na história da humanidade, transformando significativamente os modos de vida e de atuar em diferentes sociedades que constituem o mundo contemporâneo. Do mesmo modo, estas mudanças têm conduzido a variações significativas na maneira como os indivíduos sociais concebem o universo, o mundo e seus respectivos ambientes. No caso do ambiente natural, não só se apresentaram novas acepções que reposicionaram sua importância e valor através do tempo, mas também novos modelos de relação e utilização que se traduziram em impactos diretos sobre ele e sobre a humanidade.

Por mais de três séculos têm existido uma supervalorização dos avanços científicos e tecnológicos considerando-os de grande benefício para o progresso e desenvolvimento da humanidade. Contudo, nas últimas décadas do século XX, deu-se início a debates sobre a configuração de uma crise ambiental promovida pela ação humana, e potencializada sob a lógica moderna de desenvolvimento e, em função dele, com a aplicação das tecnociências.

Leff (2010) argumenta que a crise ambiental resulta da racionalidade instrumental da ciência moderna, ou seja, ela deriva da crise do pensamento moderno, que produziu uma ordem de coisificação e fragmentação do saber, como um mecanismo para dominar e controlar o mundo. Neste sentido, o risco ecológico requer novos saberes como base para a reconstrução social, sendo que os principais questionamentos se direcionam para as origens desta racionalidade e como esses conhecimentos estão em crise por ter permitido a configuração de um modelo de desenvolvimento insustentável. O autor considera que é urgente iniciar transformações na ordem simbólica da modernidade, tanto do poder como do saber, questionando em consequência o projeto epistemológico moderno (LEFF, 2013).

Ainda, segundo Giddens (2012), o projeto da racionalidade moderna, que teve início no século XVII com a emergência das ciências modernas, é configurado em termos sociopolíticos a partir das fortes mudanças trazidas em meados do século XVIII, explicitadas pela Revolução Francesa e de seus pressupostos iluministas de racionalidade e liberdade, inter-relacionados com o processo emergente de industrialização desde a Inglaterra, o que acabou desmantelando modos tradicionais de vida de populações da época. Estas mudanças são representações de novas dinâmicas que introduziram a modernidade como fenômeno social, tanto em seus aspectos materiais como em seus 
consequentes resultados simbólicos, nos quais as ciências e as artes técnicas assumiram um papel importante. Sem dúvida, tais materializações, tanto simbólicas como técnicas, impactaram no modelo de relacionamento do homem com a natureza, assim como nos processos de transformação do ambiente natural, como também, da própria natureza humana.

Essa dinâmica de mudanças é explicitada pelo conceito de falha metabólica por Karl Marx (2010), já no século XIX. Para esse autor, haveria uma relação metabólica do homem com a natureza, mediada pelo trabalho, pois o homem, ao se relacionar com a natureza para prover sua existência, transforma-a e nesse processo transforma a si mesmo. No entanto, a partir da industrialização no contexto capitalista, rompeu-se com essa relação metabólica, pois separa o ser humano da natureza, com excessiva concentração de pessoas na cidade - lócus da indústria e do trabalho moderno - e consequente exploração dos trabalhadores e da natureza, tornando esse modo de produção insustentável (FOSTER, 2005).

Partindo da tese da insustentabilidade do projeto moderno de desenvolvimento, baseado na ciência, técnica e tecnologia, centrais na configuração da modernidade, neste artigo apresentar-se-á um debate que relaciona a existência da crise socioambiental evidenciada nos últimos 60 anos, definida por uma série de autores como uma crise do pensamento e de práticas modernas, tendo como central o paradigma das ciências e da sua aplicação por meio das técnicas em um processo que origina tais crises sociais e ambientais. Nesse contexto, tratar-se-á, por um lado, da geração de riscos e ameaças latentes para a humanidade e o planeta a partir desta lógica, que aciona a ciência e tecnologia em esferas radicalmente diferentes das sociedades precedentes; por outro, do fato paradoxal da confiança que ainda persiste e se renova na ciência e na tecnologia moderna, como uma opção para reverter os danos ambientais e os impactos sociais. Por fim, serão problematizadas tais proposições visando alternativas socioambientais que conjuguem os aspectos humanos (pensamento e práticas) e ecológicos na perspectiva da sustentabilidade.

\section{A ciência moderna, a técnica e a tecnologia e seu impacto na transformação da natureza}

O acionar tecnocientífico impactou na transformação do ambiente humano e natural, com o aperfeiçoamento das técnicas de trabalho, e do aproveitamento e uso do 
ambiente natural. Desde as atividades agrícolas e pecuárias, passando pelas de extração como o desflorestamento e mineração, até as de manufatura e de alta tecnologia, todas têm sofrido grandes transformações que têm permitido o aumento da produtividade e da eficiência na busca de maiores ganhos econômicos. Tanto a ciência, como as técnicas e a tecnologia, têm sido então um elemento inseparável do trabalho humano, e isto, seguindo as ideias de Marx (2010), pode ser considerado como um processo no qual estas reconfiguram (a ponto de romper) o processo metabólico, que ele define como o resultado do trabalho que se traduz em um processo no qual o homem se relaciona com a natureza.

O trabalho é, em primeiro lugar, um processo entre o homem e a natureza, um processo em que o homem medeia, regula e controla seu metabolismo com a natureza. $\mathrm{O}$ homem enfrenta a própria matéria natural como um poder natural. Põe em movimento as forças naturais que pertencem à sua corporeidade, braços e pernas, cabeça e mãos, a fim de se apoderar dos materiais da natureza sob uma forma útil para sua própria vida. Ao operar por meio desse movimento sobre a natureza exterior a ele e transformá-la, transforma, por sua vez, sua própria natureza. Ele desenvolve as potências que nela jazem latentes e submete o jogo de suas forças a seu próprio domínio (MARX, 2010, p. 326-327).

Seguindo a concepção de Marx, as técnicas têm ocupado um papel preponderante no uso da natureza como fonte material ou de recursos necessários para a subsistência humana, assim, também têm contribuído no objetivo do homem de dominar as forças da natureza. Isto sob um duplo processo de transformação, no qual, o homem não só transforma o ambiente natural que o rodeia, mas também transforma sua própria natureza interna.

Contudo, é possível afirmar que desde o contexto no qual Marx desenvolveu suas apreciações e ideias até hoje, o salto exponencial das artes mecânicas e da tecnologia tem inserido mudanças significativas que recolocaram o modelo por ele proposto. $\mathrm{Na}$ atualidade, mais que utilizar sua corporeidade física, são as artes mecânicas e o produto das tecnociências que são postas em movimento pelo homem moderno, para se apoderar das matérias da natureza. Nesse sentido, mais que braços, pernas e mãos, hoje o homem se apoia na sua cabeça entendida como o resultado da sua produção intelectual, que tem permitido o avanço e a criação de ferramentas que facilitam a exploração dos recursos ambientais, utilizando cada vez menos mão de obra.

Isto poderia ser visto sob as influências das transformações que operam tanto externa como internamente no contexto da modernidade ocidental, dando lugar a um processo continuado de transformação da natureza, produzindo um afastamento ontológico 
entre o homem e oambiente natural. Como exemplo, pode-se considerar a comparação sobre as possibilidades de desflorestação ou desmatamento no século XIX e as atuais, na qual é possível eliminar um bosque em minutos com a participação de poucos trabalhadores e a utilização de maquinários incríveis como as Feller Buncher ou Harvester, dentre outras.

\begin{abstract}
A tecnologia nesse esquema de coisas trata a natureza como matériaprima, não como um mundo que emerge de si mesmo, uma physis, mas antes como materiais que esperam a transformação no que quer que desejemos. Esse mundo é compreendido mecanicamente e não teleologicamente. Está ali para ser controlado e usado sem qualquer propósito interno. O Ocidente fez avanços técnicos enormes com base nesse conceito de realidade (FEENBERG, 2013, p. 54).
\end{abstract}

Existe então uma ordem de relações nas quais, por meio da tecnologia, a lógica moderna fragmenta e hierarquiza a relação homem - natureza, baseada no aproveitamento dos recursos naturais em função do progresso e do desenvolvimento econômico e social, sendo este o caráter compartilhado com o projeto moderno. Assim, tanto a ciência como as artes técnicas, foram definidas como inerentes ao progresso e ao desenvolvimento de qualquer nação que tivesse a pretensão de ser considerada moderna. Por sua vez, Smith (1994) referencia a consolidação do determinismo tecnológico no século XVIII e enfatiza como essa concepção, que se iniciou na Europa, translada-se, por exemplo, aos Estados Unidos de América, a partir de um processo material e simbólico que se insere pela cultura.

Nesse processo de expansão do projeto moderno, expande-se também, o que Marx, segundo Foster (2005), chama de falha metabólica, ou seja, as relações campo e cidade promovida pela industrialização que, por um lado, gera poluição derivada da concentração humana e de resíduos, e de outro o esvaziamento do campo e perda de resíduos fertilizadores do solo e da relação metabólica homem e natureza. Esses são exemplos do rompimento do metabolismo nas relações dos seres humanos com a natureza, causados pelo capitalismo, movido pela ciência, tecnologia e técnica modernas, que submetem os trabalhadores e a natureza aos ditames da lucratividade.

Nos últimos 60 anos, as críticas se ampliaram e diversas manifestações, fatos e situações, explicitaram que não existe uma condição "branda" ou inofensiva na ciência nem em seu acionar técnico, pois o modo de operar a tecnociência orientada por parâmetros do progresso econômico, colocou em situações de risco e desastres que terminaram com a vida de determinadas populações, como também tem deixado em 
situação de ameaça a população mundial, espécies vegetais, animais, ou seja, o ambiente como um todo. Diante de tais riscos busca-se apresentar parte deste debate desde a perspectiva da formulação de riscos inserido no debate desenvolvido por Beck e Giddens no campo da sociologia reflexiva no âmbito das Ciências Sociais, considerando a problemática ambiental.

\section{A geração de riscos e o lado sombrio da modernidade, a ciência moderna e a tecnologia}

Um dos enfoques que pode ser considerado apropriado quanto à leitura de como a racionalidade moderna lança mão do aparelho tecnocientífico e cria um conjunto de riscos para a sociedade humana, é a perspectiva da formulação de riscos, apresentada, principalmente, por Anthony Giddens e Ulrich Beck. Eles reconhecem nos riscos gerados pela modernidade um elemento fundamental para o entendimento de suas consequências.

No caso de Giddens, ele parte das impressões que definem comumente à modernidade, sendo essa como uma arma de dois gumes, no sentido de que ela tem criado maiores oportunidades para o desfrute de uma vida mais segura e de proteção com respeito ao que ele denomina como "riscos externos", bem como de comodidades que fazem a vida ainda mais gratificante em relação às sociedades tradicionais; mas também tem criado um conjunto de novas ameaças, ou seja, "riscos fabricados" para a sociedade e o ambiente natural, o que ele descreve como o lado sombrio da modernidade (GIDDENS, 1991).

Um elemento importante desta perspectiva é que reconhece e define os riscos ambientais como uma criação da mão humana, relacionada à aplicação da ciência, à lógica da modernidade e sua reprodução material, aos modelos de consumo, e a forte pressão que isto exerce sobre o ambiente natural, entre outros.

Giddens afirma que o mundo no qual se vive hoje está carregado de perigos, fato contrário à crença de que a modernidade criaria um mundo mais seguro e uma ordem social mais feliz (GIDDENS, 1991). Nesse sentido, e ante a ausência de certezas sobre as configurações e envolvimentos reais desses riscos fabricados:

[...] os indivíduos, países e organizações transnacionais devem negociar os riscos na medida em que fazem escolhas sobre como devemos viver nossas vidas [...] cada indivíduo se vê forçado a tomar decisões sobre quais riscos está preparado para enfrentar (GIDDENS, 2012, p.148). 
Desta maneira, este autor realça o sistema de confiança "abstrata" que constrói a modernidade sobre a base da inter-relação entre peritos e leigos: entre quem dirige e controla os sistemas técnicos e quem não tem conhecimento total deles e colocam sua confiança sobre a base de conhecimentos peritos acerca do seu funcionamento e seguridade. Na verdade, a maioria da população não tem conhecimento aprofundado sobre os riscos que assumem com a utilização de certos objetos de uso cotidiano. A maior parte da população mundial, por exemplo, desconhece os métodos técnicos utilizados para a produção e transformação a grande escala dos alimentos que chegam à sua mesa e como eles podem ter uma incidência negativa na sua saúde.

Da mesma maneira, existem outros riscos que estão latentes sobre grandes populações, a biosfera, ou espaços naturais, e que passam inadvertidas seja pelo não acesso as informações técnicas, seja porque estejam paralisados diante de tamanhos riscos, pois na história revelam-se fatos que explicitam tais riscos, como o caso de Chernobyl em 1986, o desastre de Exxon Valdez de 1989 no Alaska, a tragédia de gás de Bhopal na Índia em 1984 e, recentemente, Brumadinho no Brasil em janeiro de 2019, entre outros. Isto sem fazer menção aos riscos que se estruturam sobre todo o globo e sobre a vida tal como a temos conhecido até agora, como os trazidos pelo aquecimento global, danos na camada de ozônio, degradação dos solos, a crescente contaminação das reservas de água doce, entre outros. Esses danos são produzidos pela mão do homem através de efeitos previstos e imprime ditados, segundo Giddens, pelos sistemas científicos e tecnológicos baseados na lógica moderna e de modernização.

Com base em tais fatos, Hannigan afirma que:

Ao nível popular, a erosão da fé na ciência foi desencadeada por uma progressão de desastres nucleares e químicos ficcionais ( $O$ Síndrome da China) e reais (Bhopal, Chernobyl, Love Canal, Three Mile Island), nos quais aqueles que têm o controle das tecnologias pareciam não saber o que estavam a fazer, optando, pelo contrário, por esconder a verdade (HANNINGAN, 1995, p. 233).

Contudo, a erosão da confiança na ciência não se concretizou como um fato absoluto no âmbito popular, tal como se tem dito e argumentado até agora. Ainda que os debates sobre a qualidade falível da ciência e da tecnologia, bem como sua capacidade de errar com consequências altamente perigosas ficaram demonstradas na percepção de cientistas e de parte da população mundial. É possível afirmar que tais discussões tem tido maiores impactos nas arenas das ciências e dos ambientalistas, o que não representa a 
maioria da população mundial, cuja percepção tem na tecnologia confiança nas soluções por ela trazidas e a mantém em uma posição relevante diante de tais fatos.

A permanência desse estado de supervalorização da tecnologia e das tecnociências pode ser compreendida a partir do seu processo histórico de consolidação e da construção de uma narrativa que as definiu como motor das mudanças mais significativas da história. Juntamente com a apreciação acima mencionada de Giddens e Hannigan, sobreos efeitos gratificantes na vida cotidiana trazidos pela modernidade, Marx e Smith (1994) afirmam que milhões de pessoas no mundo têm vivido sob o incrível poder transformador da tecnologia que atua sobre a base da ciência moderna, principalmente as denominadas por eles como "ciências radicalmente novas". Dizem os autores: "Por cerca de três séculos, a experiência direta desse poder tem sido uma característica quase universal da vida nos países desenvolvidos e em desenvolvimento" (MARX; SMITH, 1994, p. 9-10, tradução nossa). ${ }^{4}$

Nesse sentido, o progresso das sociedades humanas relacionado com períodos históricos anteriores tem sido vinculado ao surgimento de artefatos provenientes das artes mecânicas ou técnicas, como por exemplo: a imprensa, conceituada como o invento que marcou o fim da idade média; o compasso e outros instrumentos para a navegação, considerados como as ferramentas que propiciaram a expansão e colonização europeia por grande parte do globo terrestre; as tecnologias de comunicação, como a internet, os novos mecanismos de transporte, entre outros elementos, que facilitaram o deslocamento das relações econômicas e sociais, considerados propulsores da globalização; e assim por diante.

Para Marx e Smith um fato que contribuiu na consolidação da narrativa que deu uma alta valorização aos efeitos da tecnologia e as artes mecânicas e técnicas foi a elaboração de um conjunto de mini-fábulas que permearam a versão popular recebida da história moderna sobre a base de uma “[...] simples ainda que altamente plausível estrutura narrativa de um antes e depois" (MARX; SMITH, 1994, p. 10, tradução nossa). ${ }^{5}$ Nesse sentido, os autores afirmam que:

A estrutura dessas narrativas populares transmite uma sensação vívida da eficácia da tecnologia como força motriz da história: uma inovação técnica aparece de repente e faz com que coisas importantes aconteçam. [...] Tomadas em conjunto, essas narrativas do antes e depois dão

\footnotetext{
4 "For some three centuries, direct firsthand experience of that power has been a well-nigh universal feature of life in developed and developing countries."

5 “[...] simple yet highly plausible before-and-after narrative structure."
} 
credibilidade à ideia da "tecnologia" como uma entidade independente, um agente de mudança virtualmente autônomo (MARX; SMITH, 1994, p. 9-10, tradução nossa). ${ }^{6}$

Além disso, a "ideologia da técnica" tem mantido uma constante defesa na busca de consolidar sua importância no devir histórico da humanidade, bem como, de seu papel na busca do progresso e desenvolvimento do mundo moderno. Nesse sentido, Vieira Pinto (2005) escreve que:

[...] restritos grupos de "técnicos" nas mais variadas operações julguemse habilitados a dizer em que consiste a técnica e que papel "deve" desempenhar nas relações entre homens. [...] cultivando o princípio filosófico, vagamente percebido, segundo o qual a técnica constitui o motor do processo histórico, [...] as transformações que irão melhorar a sociedade, só podem originar-se do desenvolvimento da técnica, do emprego de novos e melhores modos de atuação no trato dos negócios humanos. [...] Convém observar haver em toda ideologização que confere à técnica o papel de motor da história, qualquer que seja a modalidade de pensamento pela qual se incida nessa ingenuidade, a crença "homeopática” aqui denunciada (VIEIRA PINTO, 2005, p. 230).

Deste modo, a valorização dos benefícios do desenvolvimento moderno e sua interrelação com a modernidade, incidindo sobre o individual, permitiram que se ignorassem os efeitos negativos de alguns avanços científicos e tecnológicos e, em consequência, tem permitido ignorar esse impacto que tal modelo de desenvolvimento produz sobre o ambiente natural e social. De fato, para alguns cientistas e teóricos tais efeitos, bem como as questões ambientais produzidas por eles, foram concebidos como algo que poderia ser superado ou "[...] ultrapassado resolutamente e com engenho" (HANNIGAN, 1995, p. 21).

Ulrich Beck afirma que a produção social de riquezas no contexto atual é inerente à produção de riscos, pelo qual se passou de uma lógica da distribuição das riquezas à de distribuição de riscos gerados pela modernização, a qual define como:

[...] o salto tecnológico de racionalização e a transformação do trabalho e da organização, englobando para além disto, muito mais: a mudança dos caracteres sociais e das biografias padrão, dos estilos e formas de vida, das estruturas de poder e controle, das formas políticas de opressão e participação, das concepções de realidade e das normas cognitivas. (BECK, 2011, p. 23).

\footnotetext{
6 "The structure of such popular narratives conveys a vivid sense of the efficacy of technology as a driving force of history: a technical innovation suddenly appears and causes important things to happen. [...] Taken together, these before-and-after narratives give credence to the idea of "technology" as an independent entity, a virtually autonomous agent of change."
}

Rev. Eletrônica Mestr. Educ. Ambient. Rio Grande, v. 37, n. 1, p. 27-46, jan/abr. 2020.

E-ISSN 1517-1256 
Neste sentido, Beck assegura que as forças da produção industrial têm criado uma "sociedade de risco mundial" e que estes riscos são uma questão central que transcendem fronteiras nacionais. Independentemente de onde a produção industrial produza danos ambientais, as consequências podem repercutir inclusive em lugares mais afastados, como o caso das chuvas ácidas. Do mesmo modo, os países desenvolvidos ou ricos não estão isentos de sofrer os efeitos da degradação ambiental.

Os preceitos e conceitos trazidos pela perspectiva da formulação de riscos, o próprio conceito do risco, de ameaça, assim como da sociedade do risco, têm sido realmente significativos na ampliação dos alcances dos debates ambientalistas, considerando em grande medida a participação do acionar científico e tecnológico na geração de tais riscos ou ameaças. Nesse sentido, a Sociologia tem contribuído na elaboração de um novo ponto de análise sobre o desenvolvimento a partir dos avanços tecnocientíficos baseados na racionalidade moderna que deu um aporte para questionar e romper a continuidade de uma fé cega nesse modelo desenvolvimentista. Mas ainda é importante a socialização destes aportes nas esferas que estão além das arenas dos cientistas e ambientalistas, pois é nesses espaços que ainda existe uma supervalorização das artes mecânicas e das tecnociências como garantidoras de progresso e desenvolvimento. Nesse sentido, constrói-se uma teleologia que credita à ciência e a tecnologia o poder de sanar erros e falhas humanas, não reconhecidas como efeitos produzidos por elas mesmas.

\section{Crítica ao otimismo na ciência e tecnologia "ecologizadas"}

Reconhecendo as controvérsias referentes aos riscos e as ameaças configuradas pela modernização, decorrentes da ciência e da tecnologia, as discussões giram em torno das ações que devem ser empreendidas em função de deter e corrigir tais perigos, principalmente os que vêm incidindo na degradação da vida humana e da natureza. A possibilidade do que tem sido chamado de desenvolvimento sustentável ganhou força a partir das grandes Conferências Mundiais promovidas pela ONU (Estocolmo 1972, Eco-92 no Rio de Janeiro, Rio + 10 na África do Sul e Rio +20 no Rio de Janeiro), passa a ser considerado uma necessidade, pois as previsões tecnocientíficas sobre os danos ao ambiente colocam que a natureza não terá possibilidade de dar resposta aos crescentes ritmos de consumo (ciclo que incorpora a produção e circulação de bens e serviços e o consumo individual e coletivo) que exercem pressão sobre os recursos naturais. Do mesmo 
modo, o planeta estaria muito comprometido com as consequências dos efeitos contaminantes das atividades industriais.

Seguindo Cutcliffe

[...] A reunião da Comissão Mundial sobre Meio Ambiente e Desenvolvimento, presidida pela norueguesa Gro Brundtland, apresentou o relatório Nosso Futuro Comum, que identificava a necessidade e centrava sua atenção no "desenvolvimento sustentável" como uma via para construir uma ponte entre as preocupações com o meio ambiente e os interesses dos países em desenvolvimento em relação à viabilidade econômica. Essa foi a temática que se tratou e ampliou durante a Cúpula da Terra no Rio de Janeiro em 1992, patrocinada pelas Nações Unidas, e que deu lugar, entre outras coisas, à assinatura do tratado internacional para a proteção da diversidade (CUTCLIFFE, 2003, p. 10, tradução nossa $)^{7}$.

Dentro das opções para atingir esse modelo de desenvolvimento sustentável encontra-se ainda a valorização e fé atribuída à ciência e a tecnologia, às quais lhes são outorgadas um caráter humanizado e ecológico, capaz de frear e corrigir à degradação ambiental e o desequilíbrio econômico entre países e indivíduos. Esse modelo baseado em técnicas ecológicas e responsáveis com o meio ambiente está presente em várias correntes técnico-científicas, uma delas é a ideia da modernização ecológica, a qual teve seus representantes presentes em todas as Conferências, desde a construção inicial da perspectiva do eco desenvolvimento (1972) até no conceito de desenvolvimento sustentável em 1992.

O ecológico do desenvolvimento sustentável está presente na concepção da modernização ecológica desde o processo de discussões e preparação da Conferência de Estocolmo em 1972 (SACHS, 2000), onde se confrontavam posições divergentes em relação à análise dos riscos e as opções políticas para enfrentá-los. A posição central conduzia a certo "otimismo epistemológico", a qual era popularmente compartilhada por políticos tanto de partidos de esquerda como de direita, e seus argumentos se orientavam para a ideia de que "[...] soluções técnicas sempre poderiam ser concebidas para garantir a continuidade do progresso material das sociedades humanas." (SACHS, 2000, p. 51). Nesta ordem de ideias, para Hannigan o que fora "esboçado com o espírito do Relatório Brundtland, a modernização ecológica, tal como o desenvolvimento sustentável, indica a

\footnotetext{
7 “[...] la reunión de la Comisión Mundial sobre Medio Ambiente y Desarrollo, presidida por la noruega Gro Brundtland, presentó el informe Nuestro Futuro en Común, que identificaba la necesidad y centraba su atención en el «desarrollo sostenible» como una vía para tender un puente entre las preocupaciones medioambientales y los intereses de los países en desarrollo en relación a la viabilidad económica. Este fue el tema que se trató y amplió durante la Cumbre de la Tierra de Rio de Janeiro en 1992, patrocinada por las Naciones Unidas, y que dio paso, entre otras cosas, a la firma del tratado internacional para la protección de la diversidad" (CUTCLIFFE, 2003, p. 10).
} 
possibilidade de ultrapassagem da crise ambiental sem deixar marcas da modernização" (HANNIGAN, 1995, p. 237).

A perspectiva teórica da modernização ecológica, seguindo as discussões propostas por Giddens:

[...] aceita que não é mais possível levar "as coisas como são", mas rejeita as soluções ambientalistas radicais que envolvem a desindustrialização. Ao contrário, ela se concentra na inovação tecnológica e no uso de mecanismos de mercado para trazer resultados positivos, transformando os métodos de produção e reduzindo a poluição na fonte (GIDDENS, 2012, p. 150).

Esta tentativa teórica desenvolvida por cientistas e acadêmicos das ciências sociais, de maneira proeminente da sociologia, considera que é necessário atingir transformações ecológicas em cinco aspectos importantes, que envolve tanto atores, como instituições e elementos da estrutura social e econômica, a saber: a ciência e a tecnologia; mercados e agentes econômicos; Estados-nações; movimentos sociais; e ideologia ecológica (GIDDENS, 2012, p. 150).

Nesse mesmo sentido, Mol (2000) entende a modernização ecológica como um processo de reestruturação ecológica focada nos atores que promovem mudanças ideológicas ou nos sistemas de crenças, nas regras e recursos utilizados e transformados por eles, contando com contribuições do Estado e do mercado para alterar as trajetórias tecnológicas, por exemplo, no controle e prevenção da poluição, bem como, em sistemas de produção e consumo ecologicamente mais sustentáveis. Em síntese, as características institucionais para que essa reestruturação ecológica seja possível, segundo o autor, seriam: sistema político aberto e democrático; ampla consciência ecológica, ONGs ambientalistas organizadas, sistema de monitoramento ambiental confiável; Estado legítimo e intervencionista, com infraestrutura socioambiental avançada e diversificada; organização de negócios e mediação; experiências e tradição no processo de negociação política.

Contudo, existem críticas ao conceito da modernização ecológica, as quais giram em torno da excessiva valorização que essa apresenta com respeito às possíveis ações na aplicação da ciência e da tecnologia para neutralizar o impacto das reproduções materiais do modelo de desenvolvimento moderno no ambiente humano e natural. A respeito disso, Hannigan (1995) ao referir à teoria da modernização ecológica, argumenta que esta:

[...] anda a passos lentos devido a um sentido de imperturbável optimismo tecnológico. [...] Contudo, a revolução do chip de silicone, a 
base desta superindustrialização, não é, de forma alguma, neutra em termos ambientais como a teoria da modernização econômica sugere (ver Mahon 1985). Além disso, vale a pena lembrar que a energia nuclear foi igualmente elogiada como uma tecnologia «limpa» até que as suas características mais indesejáveis se tornaram conhecidas (HANNIGAN, 1995, p. 238, grifos do autor).

O exemplo trazido por Hannigan faz um comparativo importante de como essa nova posição tem muito em comum com as posições que no passado se teve com respeito a uma suposta tecnologia inócua, mas que produz resíduos altamente contaminantes e possibilidades de catástrofes, seja por acidentes (nucleares) como de Chernobyl (1986) e Fukushima (2011), como pelo uso desta tecnologia para a guerra (bomba nuclear).

Por sua vez, Giddens considera que:

Os críticos consideram a modernização ecológica confiante demais em soluções tecnológicas e relativamente ignorante em relação a conflitos culturais, sociais e políticos. Provavelmente esteja correto dizer que a modernização ecológica está imbuída de otimismo tecnológico, em vez de ter uma teoria totalmente pronta de como chegar daqui até uma sociedade futura sustentável (GIDDENS, 2012, p. 151).

Pode-se afirmar que a teoria da modernização ecológica compartilha, ainda que em maior proporção, com a teoria do desenvolvimento sustentável, esse caráter otimista em ações que não necessariamente poderiam ter incidência em mudanças reais e que transcendam à realidade atual, a qual se pretende transformar. Em todo caso, é importante revisar e analisar de maneira crítica essa persistência da fé na tríade - ciência, técnica, tecnologia - sobre a base do futuro melhor que possam oferecer. Essas promessas de futuro devem ser revisadas considerando os danos que a lógica moderna e os aplicativos tecnocientíficos têm gerado na natureza, bem como o conjunto de riscos que têm se configurado para a humanidade de maneira progressiva. Deve-se considerar, em todo caso, que detrás “[...] das promessas messiânicas de transformações sociais, decorrentes do progresso da tecnologia humanizada, a difusão desse artefato tecnológico favorece a conservação do estado de coisas existentes” (VIEIRA PINTO, 2005, p. 231).

Entretanto, há que se considerar que existem posturas de teóricos relevantes que afirmam que é impossível manter o estado das coisas pelo caminho que até agora foi assumido pelo que se configura com maior aderência à vida moderna, tendo em vista os limites expostos acima e as novas propostas e olhares para superar a crise ambiental e a crise da ciência e da racionalidade moderna. Nesse sentido, vale mencionar a perspectiva 
de Leff (2010), que propõe um olhar ambiental complexo, ou um processo de construção do pensamento a partir do que ele define como a complexidade ambiental.

Seguindo os pressupostos apontados por Leff (2010), os modelos da racionalidade, epistemológica e ontologicamente impostas pelo paradigma da ciência moderna têm promovido relacionamentos dos humanos com a natureza não viável e insustentável. Nesse sentido, faz-se necessário um novo modelo que redefina essa interação homem-natureza fora da lógica dominante e hegemônica que hoje é refletida na globalização.

A concepção da complexidade ambiental proposta por Leff, vem cumprir essa função por meio da hermenêutica ambiental, que constitui um olhar pela perspectiva da complexidade, entendida como um paradigma que convida a uma forma diferente de apropriação do mundo, uma nova cosmovisão, um acionar da ciência mais ética e consciente. Isto partindo do reconhecimento da complexificação do real, do conhecimento, da produção, do tempo, das identidades e do ser. Assim também, propiciando uma pedagogia da complexidade ambiental que desmonte e desconstrua os esquemas do modelo hegemônico da racionalidade cartesiana que temos aprendido e que se têm arraigado em nossas maneiras de pensar e de conceber o mundo e a natureza. Deve-se realçar a inclusão da noção da alteridade como um caminho às práticas e relacionamentos mais responsáveis dos homens entre si e com o ambiente natural.

Tendo colocado aqui a crítica à noção do projeto moderno como único caminho possível para o desenvolvimento, conjuntamente como seu particular olhar e acionar científico e tecnológico é necessária também colocar a consideração de que outros modelos de desenvolvimentos são possíveis e coexistem hoje, ainda que estejam sob um processo de forças que tentam invisibilizá-los. Esses modelos para o caso da América Latina estão representados em um processo de resistência e luta contra esse padrão de desenvolvimento que arrasa e destrói territórios, ecossistemas, biodiversidade; que produz deslocamentos forçados, perda de identidade, desumanização e que nega os direitos das populações às suas ancestralidades, seus territórios e a sua autonomia; tudo isto contrário às promessas feitas pelo modelo hegemônico ocidental. Esses processos oferecem um caminho que Escobar (2015) denomina como de transição, ou seja, que constituem:

Contribuições importantes às transições ecológicas e culturais para o pluriverso. Essas transições são necessárias para enfrentar as múltiplas crises ecológicas e sociais produzidas pela ontologia Uni-mundistas e suas concomitantes narrativas e práticas. Ao falar de transições (como diriam muitos ativistas: para outros modelos civilizatórios verdadeiramente sustentáveis e plurais, ou transições ao pós-extrativismo 
e o imaginar alternativas ao desenvolvimento), estamos destacando a dimensão planetária das lutas locais, especialmente em face da mudança climática global (ESCOBAR, 2015, p. 94, tradução nossa). ${ }^{8}$

Nesse sentido, é importante assinalar que fora dessa visão construída secularmente pela modernidade, e seu aparelho tecnocientista e tecnológico que rouba e nega o caráter ontológico da natureza, em outras culturas, territórios e grupos sociais, existem outras possibilidades que se encaixam mais com os padrões de sustentabilidade que na atualidade se proclamam no mundo, mas somente parecem ser visualizados e promovidos principalmente aqueles que se encaixam dentro desse paradigma que tem configurado essa crise ambiental. As ações desenvolvidas por esses grupos locais, seguindo a Escobar, poderiam ser definidas [...] como formas alternativas modernas de produção - ainda como diferentes configurações modernas culturais, econômicas ecológicas, como também alternativas para a modernidade - que poderiam se denominar como configurações decoloniais da natureza, a cultura e a economia (ESCOBAR, 2011, p. 70, tradução nossa). ${ }^{9}$

Desta maneira, esses modelos merecem ser considerados e respeitados. Assim, considerando o lugar desde onde se elaborou este artigo, não se poderia deixar de fazer menção a estas possibilidades, ainda que seja como ponto de fechamento que, ao mesmo tempo, abre possibilidades para outras análises decorrentes.

\section{Conclusões}

Em que pese os fatos que têm deixado claro a inviabilidade do projeto moderno, os modelos de reprodução material, vinculados à acumulação de capital, a lógica científica e tecnológica sem uma perspectiva consciente e responsável, coloca em riscos a vida no planeta. Deve ser reconhecido que a fé no progresso e no desenvolvimento segue hoje apostando em uma proporção considerável às ciências e ao aplicativo das técnicas. Esse fato se deve a um processo contínuo e progressivo, no qual a grande narrativa trazida pela modernidade se apoiou sobre a base de um determinismo tecnológico.

\footnotetext{
8 "Contribuciones importantes a las transiciones ecológicas y culturales hacia el pluriverso. Estas transiciones son necesarias para enfrentar las múltiples crisis ecológicas y sociales producidas por la ontología Uni-Mundista y sus concomitantes narrativas y prácticas. Al hablar de transiciones (como dirían muchos activistas: a otro modelos civilizatorios verdaderamente sustentables y plurales, o transiciones al post-extractivismo y el imaginar alternativas al desarrollo), estamos poniendo de relieve la dimensión planetaria de las luchas locales, especialmente frente al cambio climático global” (ESCOBAR, 2015, p. 94).

9 “[...] como formas alternativas modernas de producción -aún como diferentes configuraciones modernas culturales, económicas y ecológicas, como también alternativas para la modernidad- que podrían denominarse configuraciones decoloniales de la naturaleza, la cultura y la economía (ESCOBAR, 2011, p. 70).
} 
$\mathrm{O}$ ambiente natural veio se transformando e degradando a um ritmo que tem simultaneamente correspondência com o avanço das tecnociências. As técnicas têm permitido a evolução das dinâmicas de produção, e mudanças na maneira em que o homem define e utiliza a natureza, do mesmo modo em que a ciência marcou relações separadas e hierarquizadas entre estes dois elementos, entre sociedade e ambiente, conhecimento científico e conhecimento vulgar, dentre outros. Este acionar cientista e técnico tem configurado também um conjunto de riscos e perigos para a humanidade cujas possíveis consequências não têm sido plenamente determinadas. Tais fatos traduziram-se em um cenário de crise socioambiental.

Por uma parte definiu-se a existência de uma crise ambiental, e por outra, inerente a ela, definiu-se a crise da modernidade. Ambas são trasladadas por diferentes autores para o seio das ciências, as quais devem adequar seus modos de atuar na busca de enfrentar os efeitos negativos que têm materializado tais crises. Isto implicaria também na redefinição dos modelos de desenvolvimento e das ideias que compõem as visões de progresso, que ainda estão enraizadas e entrelaçadas com a tecnologia e a modernização.

A possibilidade de que por meio das ciências e das técnicas possa ser revertido os danos causados ao meio ambiente, bem como frear a geração de riscos gerados pela mão humana, são perfeitamente discutíveis a partir de uma perspectiva realista. Isso porque existe o risco de que a ideia da modernização ecológica ou a tese de uma tecnologia humana, possa constituir só uma espécie de fé que mantenha a situação atual à espera de ações que nunca cheguem a se realizar enquanto persista o objetivo fundamental da reprodução do capital, acompanhado da esperança em uma solução que tem de surgir em qualquer momento, sem se preocupar de forma efetiva e propositiva com o futuro da vida no planeta.

Vale dizer que ainda existe uma dívida com os grupos sociais que resistem aos efeitos e as imposições da modernidade, da ciência e da tecnologia, e que mostram que outros modelos de relacionamento com a natureza sob a base de uma racionalidade carregada de seus sentidos epistêmicos e ontológicos particulares são possíveis, que existem e que merecem ser respeitados. Nesse sentido, esses modelos econômicos, culturais de desenvolvimento alternativo que se produzem desde espaços locais determinados, como os da América Latina, apresentam maiores níveis de sustentabilidade e pluralidade, e convidam à superação da colonialidade secular imposta neste território. 


\section{Agradecimentos}

Este trabalho foi realizado com a contribuição de bolsa de estudos recebida no âmbito do Programa de Aliança para a Educação e a Capacitação da Organização de Estados Americanos e o Grupo Coimbra de Universidades Brasileiras (PAEC OEAGCUB), com o financiamento da Coordenação de Aperfeiçoamento de Pessoal de Nível Superior (CAPES). Agradeço aos organismos antes mencionados pela oportunidade oferecida. Do mesmo modo, agradeço ao Programa de Pós-Graduação em Desenvolvimento Regional (PPGDR), da Universidade Tecnológica Federal do Paraná (UTFPR) e ao seu distinto corpo docente e discente.

\section{Referências}

BASTOS, João Augusto Leão de Almeida. Educação e Tecnologia. In: Tecnologia e Interação. Curitiba: PPGTE/CEFET-PR, 1998.

BECK, Ulrich. Sociedade de risco: rumo a uma outra modernidade. 2. ed. São Paulo: Editora 34 Ltda., 2011.

BECK, Ulrich; GIDDENS, Anthony; LASH, Scott. Modernização reflexiva: política, tradição e estética na ordem social moderna. São Paulo: Editora da Universidade Estadual Paulista, 1994.

ESCOBAR, Arturo. Ecología Política de La globalidad y la diferencia. In: ALIMONDA, Héctor. (Coord.). La Naturaleza colonizada. Ecología política y minería en América Latina. Buenos Aires: CLACSO, 2011.

ESCOBAR, Arturo. Territorios de diferencia: la ontología política de los "derechos al territorio". Desenvolvimento e Meio Ambiente. Curitiba, vol. 35, p. 89-100, dezembro 2015 .

FEENBERG, Andrew. O que é a filosofia da tecnologia? Disponível em: https://www.sfu.ca/ andrewf/books/Portug_O_que_e_a_Filosofia_da_Tecnologia.pdf. Acessado em dezembro de 2013.

CUTCLIFFE, Stephen Hormes. La emergencia histórica de CTS como campo académico. In: Ideas, máquinas y valores: los estudios de Ciencia, Tecnología y Sociedad. México: Anthropos Editorial; Universidad Nacional Autónoma de México, 2003.

CUTCLIFFE, Stephen Hormes. Racionalidade subversiva: tecnologia, poder e democracia. In: NEDER, Ricardo Toledo. A teoria crítica de Andrew Feenberg: racionalização democrática, poder e tecnologia. Brasília: UNB/CAPES, 2013. 
FOSTER, John Bellamy. A ecologia de Marx. Rio de Janeiro: Civilização Brasileira, 2005.

GIDDENS, Anthony. As consequências da modernidade. São Paulo: Editora UNESP, 1991.

GIDDENS, Anthony. Sociologia. Porto Alegre: Penso, 2012.

GIDDENS, Anthony; SUTTON, Philip W. Conceitos essências da sociologia. São Paulo: Editora Unesp, 2016.

GUIVANT, Júlia Sílvia. Os debates entre realistas e construtivistas sociais na sociologia ambiental: implicações para o desenvolvimento rural sustentável e participativo. VI Congresso da ALASRU. Porto Alegre, 2002.

HANNIGAN, Jhon. Sociologia ambiental: a formação de uma perspectiva social. Lisboa: Instituto Piaget, 1995.

LEFF, Enrique. Epistemologia ambiental. 5 ed. São Paulo: Cortez, 2010.

LEFF, Enrique. Sustentabilidad y racionalidad ambiental: hacia otro programa de sociología ambiental. Revista Mexicana de Sociología. México D.F., vol. 73, n. 1, p. 127154, enero-marzo 2011.

LEFF, Enrique. Ecologia política: uma perspectiva latino-americana. Desenvolvimento e Meio Ambiente. Curitiba, vol. 27, p. 11-20. Editora UFPR, jan./jun. 2013.

MARX, Leo; SMITH, Merrit Roe. Introduction. In: SMITH, Merrit Roe; MARX, Leo. Does technology drive history?: the dilema of technological determinism. Baskerville: MIT, 1994.

MARX, Karl. El capital. V. I, tomo 1. Madrid: Siglo XXI de España Editores, 2010.

MOL, Arthur. A globalização e a mudança dos modelos de controle da poluição industrial: a teoria da modernização ecológica. In: HERCULANO, S.; PORTO, M.; FREITAS, C. Qualidade de vida e riscos ambientais. Niterói: EdUFF, 2000.

MORIN, Edgar. Ciência com Consciência. 13. ed. Ed. Bertrand Brasil: Rio de Janeiro, 2010 .

NEDER, Ricardo Toledo. O que (nos) quer dizer a teoria crítica da tecnologia? IN: NEDER, Ricardo T. A teoria crítica de Andrew Feenberg: racionalização democrática, poder e tecnologia. Brasília: UNB/CAPES, 2013.

SMITH, Merrit Roe. Technological Determinism in American Culture. In: SMITH, Merrit Roe; MARX, Leo. Does technology drive history? The dilema of technological determinism. Baskerville: MIT, 1994.

SACHS, Ignacy. Caminhos para o desenvolvimento sustentável. Coleção Idéias Sustentáveis. Rio de Janeiro: Garamond, 2000. 
UNIVERSIDADE TECNOLÓGICA FEDERAL DO PARANÁ. Normas para elaboração de trabalhos acadêmicos. Curitiba: UTFPR, 2008.

VIEIRA PINTO, Álvaro. O Conceito de Tecnologia. Volume 1. Rio de Janeiro:

Contraponto, 2005.

Submetido em: 30-07-2019.

Publicado em: 17-04-2020 